\title{
Rainfall and temperature projections and their impact assessment using CMIP5 models under different RCP scenarios for the eastern coastal region of India
}

\author{
S. Vijayakumar ${ }^{1}$, A. K. Nayak ${ }^{1, *}$, A. P. Ramaraj $^{2}$, C. K. Swain ${ }^{1}$, \\ V. Geethalakshmi ${ }^{3}$, S. Pazhanivelan ${ }^{3}$, Rahul Tripathi ${ }^{1}$ and N. S. Sudarmanian ${ }^{3}$ \\ ${ }^{1}$ ICAR-National Rice Research Institute, Cuttack 753 006, India \\ ${ }^{2}$ International Crops Research Institute for the Semi-Arid Tropics, Hyderabad 502 324, India \\ ${ }^{3}$ Tamil Nadu Agricultural University, Coimbatore 641 003, India
}

Trend analysis of annual rainfall over the coastal districts of Odisha, India showed statistically nonsignificant increasing trend in all districts, except Ganjam. Whereas the maximum and minimum temperature showed significant increasing trend. Warming in these districts is mainly due to increasing minimum temperature during summer and rainy season, and maximum temperature during winter. Future climate projection results revealed, the annual mean rainfall is expected to change by $0.1-2.2 \%,-0.3-0.7 \%$ and $1.5-3.2 \%$ (RCP 4.5), and 3.6-7.9\%, 3.7-6.6\% and 8.5-14\% (RCP 8.5) during the near (2011-39), mid (2040-69) and late (2070-99) centuries respectively. Anticipate climate change will have a marginal impact on total rainfall, and a major impact on its distribution. The annual mean minimum temperature is expected to increase by $0.60-0.73^{\circ} \mathrm{C}, 0.71-0.88^{\circ} \mathrm{C}$, $1.20-1.42^{\circ} \mathrm{C}(\operatorname{RCP} 4.5)$, and $1.77-2.14^{\circ} \mathrm{C}, 1.56-1.68^{\circ} \mathrm{C}$, 3.06-3.73 ${ }^{\circ} \mathrm{C}$ ( $R C P$ 8.5) during near, mid and late centuries respectively. Similarly, the annual mean maximum temperature is expected to increase by $0.61-0.66^{\circ} \mathrm{C}, 0.68-0.72{ }^{\circ} \mathrm{C}$ and $1.35-1.55^{\circ} \mathrm{C}$ (RCP 4.5), and $1.79-1.97^{\circ} \mathrm{C}, 1.73-2.01^{\circ} \mathrm{C}$ and $3.08-3.44^{\circ} \mathrm{C}(\mathrm{RCP}$ 8.5) during near, mid and late centuries respectively. Season-wise projection revealed that the change in rainfall and temperature is expected to be more in winter and summer under both the RCP scenarios. The projected future climate change will have both positive and negative impacts on agriculture. The negative impacts are expected to be more pronounced during $k$ harif in comparison to rabi.

Keywords: Climate projection, coastal districts, rainfall, temperature, trend analysis.

THE Indian state of Odisha situated on the east coast near the Bay of Bengal, is one of the most vulnerable regions in the world to climate change in terms of violent tropical

\footnotetext{
*For correspondence. (e-mail: aknayak20@yahoo.com)
}

cyclones, rainfall and temperature. This is an agriculturally predominant state housing $70 \%$ of the small and marginal farmers with poor resource endowment and who depend on monsoon for agricultural production ${ }^{1}$. In Odisha, the coastal plains are the most productive due to welldeveloped irrigation facilities and fertile land comprising alluvial soil ${ }^{2}$. However recently, the coastal plains are highly threatened and have become potentially vulnerable ecosystems to climate change ${ }^{3}$. The poor countries and poor people are the ones that suffer most from extreme events due to climate change ${ }^{4}$.

Temperature and rainfall are two important weather factors which play a major role in crop germination, growth, reproduction and yield, and subsequently agricultural production ${ }^{5-8}$. Odisha's agriculture mostly depends on the southwest monsoon (SWM) which determines the length of crop growing period, cropping pattern and profit from farming. About $76 \%$ of yearly rainfall is received in SWM (June to October) and $17 \%$ is received in summer (March to May). Any anomaly in the seasonal rainfall influences the communities which depend on farming for their livelihood. In eastern India, western Odisha was earlier known as a calamity hotspot, but now the coastal areas are also considered as a calamity hotspot due to regular occurrence of tropical cyclones, droughts, floods, heat waves, etc. ${ }^{9}$. The frequency of cyclones has increased on the Odisha coast. Multiple cyclones hit the state in quick succession. Odisha has experienced natural calamities like floods, droughts and cyclones during almost all the years since 1965. In the last 105 years, floods, droughts and cyclones have struck the state for 50,32 and 11 years respectively, and declared calamity damaged for 95 years ${ }^{10}$. With increasing greenhouse gases (GHGs), there is a high probability that the frequency of these natural calamities will increase in future ${ }^{9,11}$. Projection of future climate in advance will provide an opportunity to develop adaptation options to deal with the natural calamities. The climate models help understand and assess the rainfall and temperature extremes. 


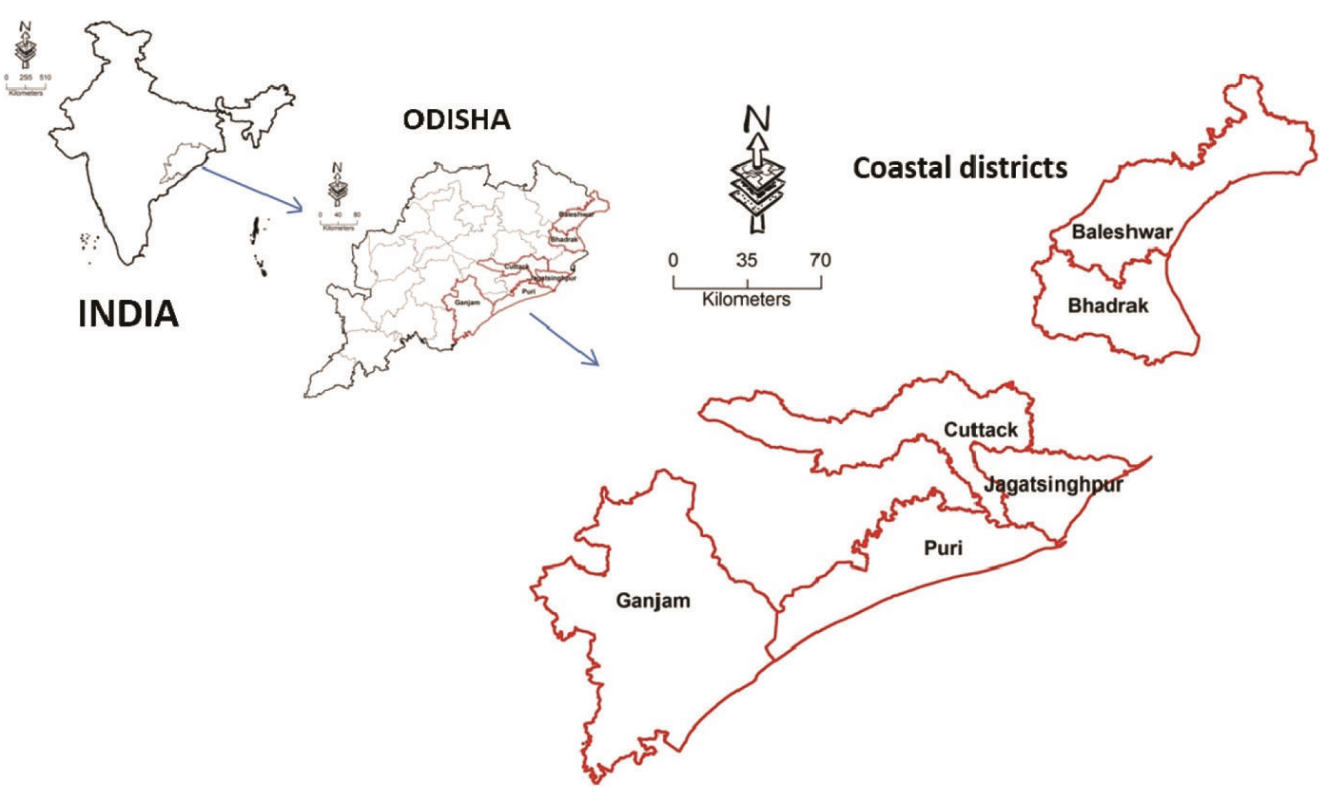

Figure 1. Map showing the study area.

Coupled Model Inter-comparison Project (CMIP5) is one among the many climate models used by Intergovernmental Panel on Climate Change (IPCC) in its Fifth Assessment Report to forecast world climate. Interestingly, most of the models under CMIP5 are representative concentration pathways (RCP)-based climate projections ${ }^{12}$. The recent literature shows a better simulation of future climate by CMIP5 models ${ }^{13,14}$. An effort has been made for climate projection for South India using CMIP5 models ${ }^{15}$. Similar projections were also made for Central and North India ${ }^{16}$. However, such projections are not available for eastern India, especially for the coastal regions. So the present study has been made with the following objectives: (1) Understanding the past rainfall and temperature trends of coastal Odisha through time-series analysis. (2) Projection of temporal and spatial differences in rainfall and temperature over Odisha coastal plains using different CMIP5 models and RCP scenarios.

\section{Materials and methods}

\section{Details of the study area}

The coastal plains of Odisha are known as the 'hexadeltaic region' or the 'gift of six rivers' as it is formed by the deltas of six rainfed rivers, viz. Subarnarekha, Budhabalanga, Baitarani, Brahmani, Mahanadi and Rushikulya. It spreads along the shore of the Bay of Bengal having maximal width in the middle coastal plain (the Mahanadi Delta), thin in the southern coastal plain (Ganjam Plain) and thinnest in the northern coastal plain (Baleswar Plain). In Odisha, coastal plains lie in the eastern part of the state between lat. 19.63 and $21.48 \mathrm{~N}$, long. 85.00 and 86.81E. Future projection has been made for all the coastal districts of Odisha, viz. Balasore, Bhadrak, Cuttack, Ganjam, Jagatsingpur and Puri, except for Kendrapara due to unavailability of weather data (Figure 1).

\section{Baseline data}

The daily meteorological data of 1980-2010 collected from India Meteorological Department (IMD), Pune, were used as baseline data for future climate projections. The data (daily rainfall, daily minimum and maximum temperatures) were subjected to quality checks like missing values, typographical errors and extreme values. The missing values were filled by calculating an average of ten days earlier and ten days after the missing period. The solar radiation was generated from daily observed sunshine hours using the Weatherman tool of Decision Support System for Agro-technology Transfer (DSSAT).

\section{Scenarios selection}

RCP 4.5 represents the moderate warming scenario of the world. According to RCP 4.5, GHG and total radiative force will reach roughly $650 \mathrm{ppm} \mathrm{CO}_{2}$ equivalent and $4.5 \mathrm{Wm}^{-2}$ respectively, before 2100 . While RCP 8.5 represents the highest warming scenario, GHG and total radiative force will reach $1370 \mathrm{ppm} \mathrm{CO}_{2}$ equivalent and $8.5 \mathrm{Wm}^{-2}$ respectively, before 2100 (ref. 17). In this study, we used RCP 4.5 and RCP 8.5 scenarios as they are representative of moderate and highest warming scenarios respectively. 
Table 1. List of climate models used and their description

\begin{tabular}{|c|c|c|c|}
\hline Model & Modelling centre (or group) & Resolution (lat.; deg) & Resolution (long.; deg) \\
\hline CCSM4 & National Center for Atmospheric Research, USA & 0.942 & 1.250 \\
\hline HadGEM2-ES & Met Office, Hadley Centre, UK & 1.250 & 1.875 \\
\hline MIROC5 & $\begin{array}{c}\text { The University of Tokyo, National Institute for Environmental Studies } \\
\text { and Japan Agency for Marine-Earth Science and Technology }\end{array}$ & 1.417 & 1.406 \\
\hline NorESM1-M & Norwegian Climate Centre & 1.895 & 2.500 \\
\hline GFDL-ESM2M & NOAA Geophysical Fluid Dynamics Laboratory & 2.000 & 2.500 \\
\hline BCC-CSM1.1 & Beijing Climate Centre, China Meteorological Administration & 2.812 & 2.812 \\
\hline CanESM2 & Canadian Centre for Climate Modelling and Analysis & 2.790 & 2.812 \\
\hline IPSL-CM5A-MR & Institute Pierre-Simon Laplace, France & 1.268 & 2.500 \\
\hline MPI ESM-LR & Max Planck Institute for Meteorology, Germany & 1.865 & 1.875 \\
\hline NorESM1-M & Norwegian Climate Centre & 1.895 & 2.500 \\
\hline
\end{tabular}

\section{CMIP5 model selection}

Climate projection using multi-model mean method improves the reliability and precision, and is a simple way to reduce biases in individual model outputs ${ }^{18}$. Thus in this study, we used a multi-model ensemble of nine global climate models (GCMs) (CCSM4, HadGEM2-ES, MIROC5, NorESM1-M, GFDL-ESM2M, BCC-CSM1.1, CanESM2, IPSL-CM5A-MR and MPI ESM-LR) for future rainfall and temperature projections. Table 1 presents detailed information about the GCMs used in this study.

\section{Study period and climate projection}

For future climate projection, the $21 \mathrm{st}$ century was divided into three-time slices, viz. near (2011-39), mid (2040-69) and end (2070-99) centuries. Using R environment, the future weather files were generated for all the models and time slice as a separate file. $\mathrm{R}$ scripts and GCM files for RCP 4.5 and RCP 8.5 were run under R console according to the procedure formulated by the Agricultural Model Intercomparison and Improvement Project (AgMIP) ${ }^{19}$. The daily output was transformed to annual and seasonal, viz. SWM (16 June to 31 October), winter (1 November to end of February) and summer (1 March to 15 June) projections using Weather Cock version 1 (ref. 20). For each district and all the models, variation from the base year (1980-2010) was estimated by computing the difference between the near, mid and late centuries with the base-year average. These scenarios of future projections are referred as 'mean change scenarios'. The ensemble of all the model outputs shows the possible range of change in rainfall and temperature over the coastal plains of Odisha.

Trend analysis of maximum temperature, minimum temperature and rainfall was performed for the period 1980-2010 using a simple linear regression method and statistical significance was determined using Trend Toolkit software ${ }^{21}$. The statistical significance of the observed trends was defined at $95 \%(P$-value $=0.05)$ significance level in this study.

\section{Results}

\section{Historical analysis}

Table 2 presents temperature and rainfall profile of the coastal plains of Odisha from 1980 to 2010. The average rainfall in the coastal plains is $1504 \mathrm{~mm}$ and it is slightly higher than the state average $(1482 \mathrm{~mm})$. The rainy season accounts for $75.9 \%(1143 \mathrm{~mm})$ of the total rainfall, followed by summer $16.6 \%(250.8 \mathrm{~mm})$ and winter $7.4 \%$ $(107.9 \mathrm{~mm})$. The study of historical rainfall data showed unimodal rainfall in the coastal plains (that is, there is only one rainy season). The distribution of rainfall was not uniform across the coastal plains. Among the districts, the highest annual rainfall was recorded in Balasore (1644 $\mathrm{mm})$ followed by Jagatsingpur (1604 mm), whereas the lowest rainfall was recorded in Ganjam (1199 mm). Season-wise distribution showed the highest mean rainfall in Jagatsingpur $(1226 \mathrm{~mm})$, Balasore (349 $\mathrm{mm})$ and Ganjam (149 $\mathrm{mm}$ ) districts during rainy, summer and winter seasons respectively. The contribution of summer and winter season rainfall to total rainfall was $13.1 \%$ and $7.2 \%$ in Puri, and $16.2 \%$ and $12.5 \%$ in Ganjam districts respectively. Though Ganjam district received the lowest amount of annual rainfall in comparison to the other coastal districts, its distribution during summer and winter was relatively higher than the districts. The mean annual maximum and minimum temperature of Odisha coastal plains was $31.6^{\circ} \mathrm{C}$ and $22.6^{\circ} \mathrm{C}$ respectively. Among the seasons, the mean maximum temperature was highest during summer $\left(34^{\circ} \mathrm{C}\right)$, whereas the mean minimum temperature was highest during rainy season $\left(25.2^{\circ} \mathrm{C}\right)$ in all the study areas. The lowest mean maximum $\left(29^{\circ}\right)$ and minimum $\left(17.6^{\circ}\right)$ temperatures were recorded in winter. Among the districts, the highest mean maximum temperature during all seasons was recorded in 


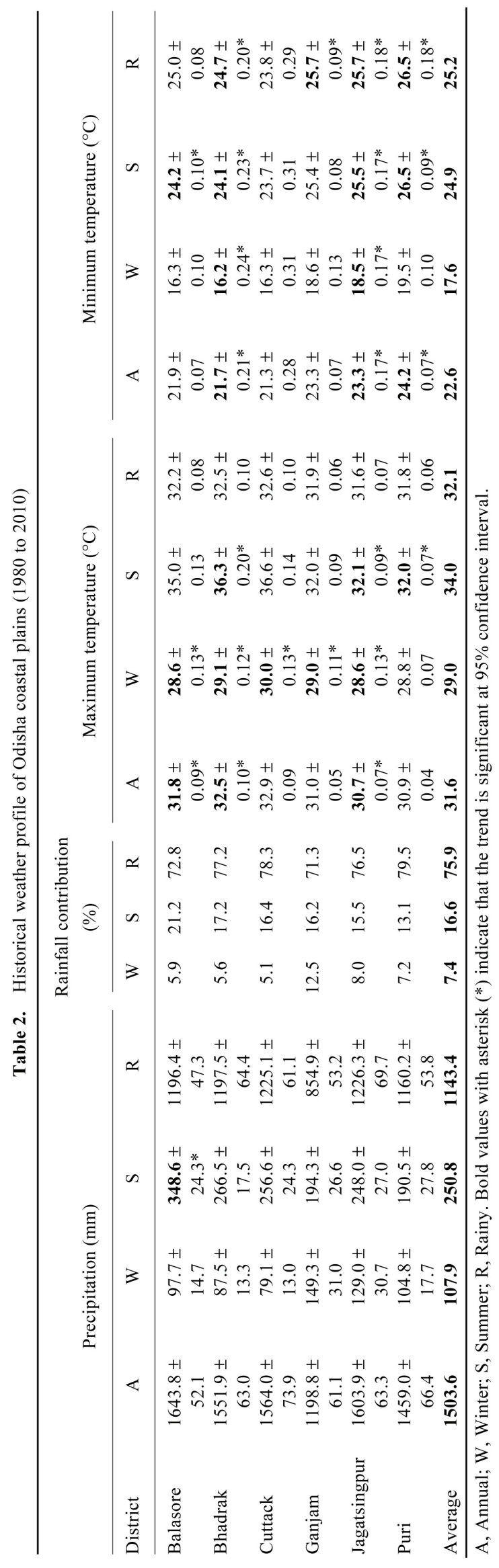



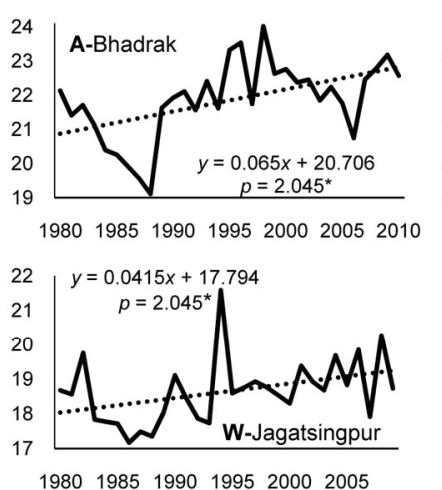

198019851990199520002005

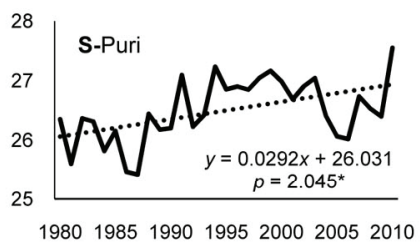

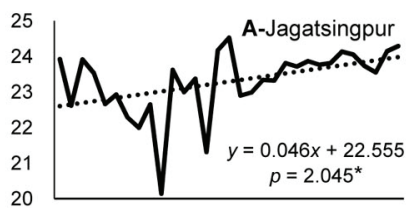

1980198519901995200020052010
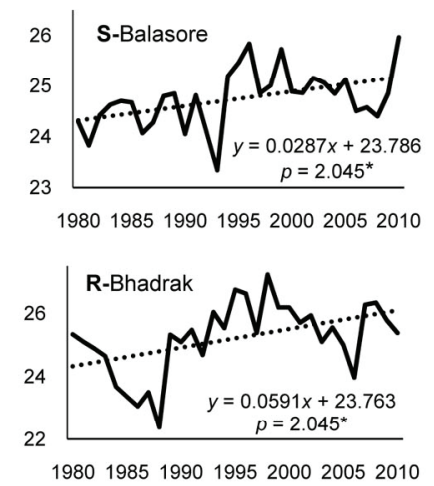

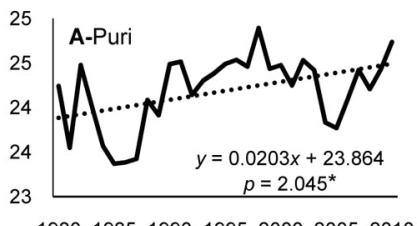

1980198519901995200020052010
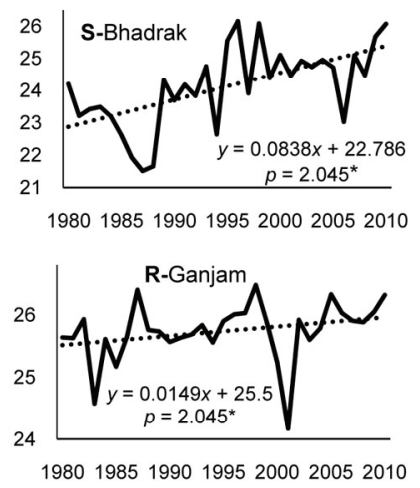
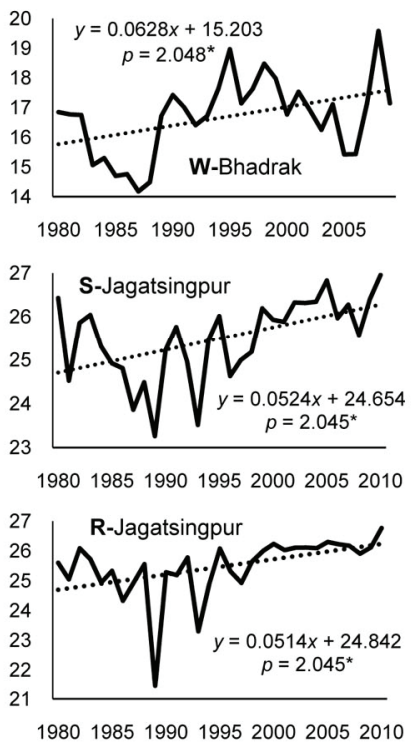

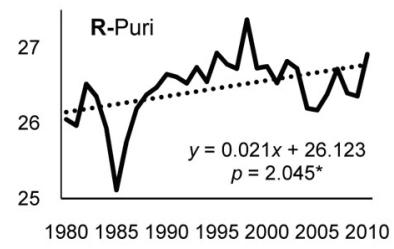

Figure 2. Annual and season-wise time-series analysis of minimum temperature in the coastal plains of Odisha, India, for the period from 1980 to 2010. Alphabets in bold before the district name indicate the season. A, Annual; W, Winter; S, Summer; R, Rainy. *Trend is significant at $95 \%$ confidence interval.

Cuttack followed by Bhadrak, whereas Jagatsingpur recorded the lowest mean maximum temperature during all seasons. Similarly, Puri district recorded the highest mean minimum temperature and Cuttack district recorded the lowest mean minimum temperature in all seasons. The average diurnal variation in temperature (difference between the minimum and maximum temperatures) during winter, summer and rainy season was $11.4^{\circ} \mathrm{C}$, $9.1^{\circ} \mathrm{C}$ and $6.9^{\circ} \mathrm{C}$ respectively. Among the districts, diurnal variation in temperature was maximum in Cuttack. The difference in mean minimum temperature between rainy season and summer was $0.7^{\circ} \mathrm{C}$. This shows that the change in minimum temperature during rainy season and summer is less in comparison to winter.

\section{Time-series analysis}

The trend analysis of rainfall in the coastal districts showed an increasing trend in all cases, except Ganjam. However, it was statistically non-significant in all the coastal districts. Whereas the trend analysis of maximum and minimum temperatures showed significant increasing trend in all the coastal districts (Figures 2 and 3). The significant increasing trend of maximum and minimum temperatures clearly shows that the coastal districts are warming over the years. Among the districts, only Bha- drak and Jagatsingpur showed statistically significant increase in minimum temperature during all three seasons (Figure 2). In Puri district, significant increasing trend of minimum temperature was recorded during rainy season and summer, while non-significant increase was recorded in winter. Similarly, in Balasore and Ganjam the minimum temperature increased significantly during summer and rainy season respectively, while non-significant increasing trend was recorded during the other seasons. With respect to maximum temperature, the increasing trend during rainy season remained statistically nonsignificant in all the coastal districts, while it was significant during summer and winter (Figure 3). Significant increase in maximum temperature during winter was noticed in all the coastal districts, except Ganjam. Similarly, in summer significant increase in maximum temperature was recorded only in Bhadrak, Jagatsingpur and Puri districts. This study clearly shows that warming in the coastal districts of Odisha is mainly due to increasing minimum temperature during summer and rainy season, and maximum temperature during winter.

\section{Future climate projections}

Tables 3 and 4 present the annual and seasonal mean maximum temperature, mean minimum temperature and 

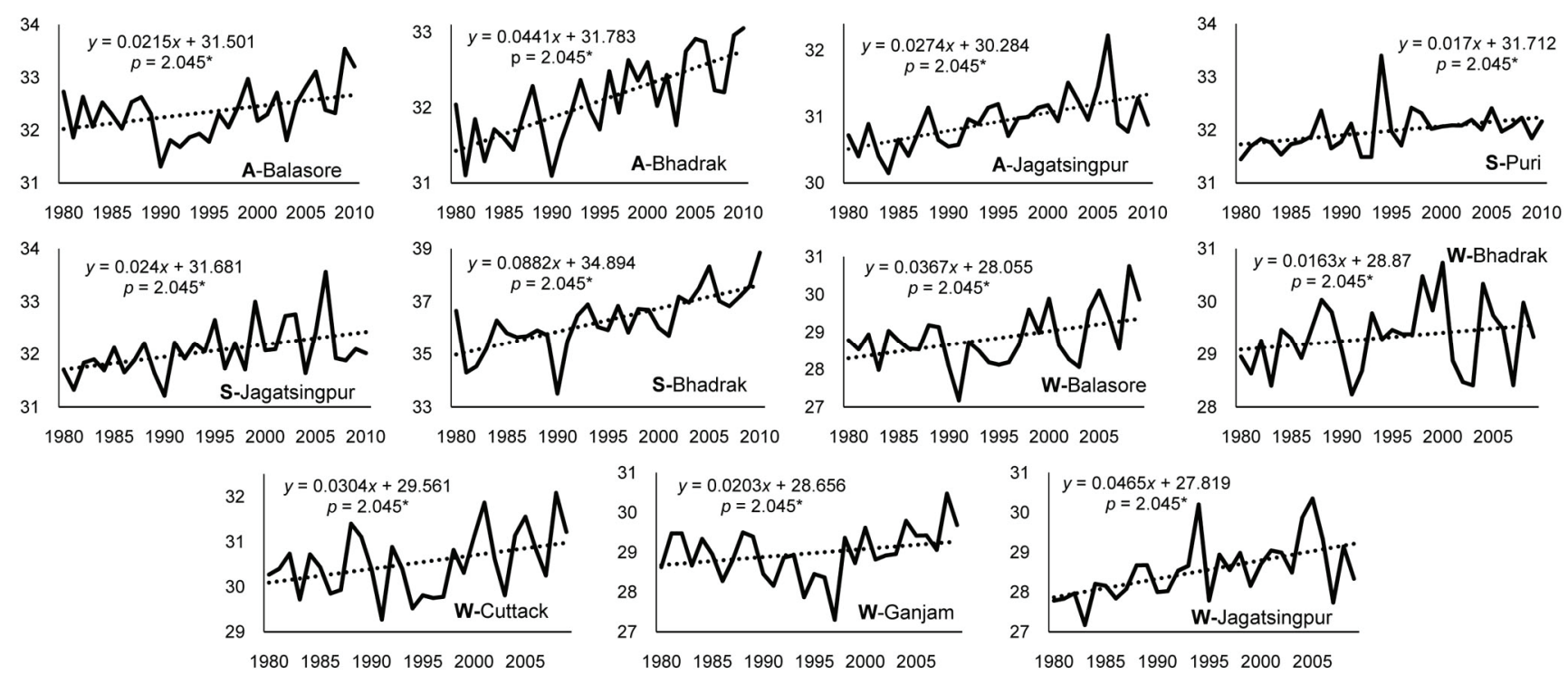

Figure 3. Annual and season-wise time-series analysis of maximum temperature in the coastal plains of Odisha for the period from 1980 to 2010 . Alphabets in bold before the district name indicate the season. A, Annual; W, Winter; S, Summer; R, Rainy. *Trend is significant at $95 \%$ confidence interval.

mean precipitation projection for the coastal districts of Odisha for RCP 4.5 and RCP 8.5 scenarios respectively. Projected rainfall shows that the expected climate change will have a marginal impact on total rainfall received in this region, while it will have a major impact on rainfall distribution during various seasons. Annual mean rainfall projection showed an increasing trend under both RCP scenarios, except in Puri district under RCP 4.5 scenario. The rate of change of annual mean rainfall under RCP 4.5 is projected to be in the range $0.1 \%$ to $2.2 \%,-0.3 \%$ to $0.7 \%$ and $1.5 \%$ to $3.2 \%$ during the near, mid and late centuries respectively, over the baseline years (1980-2010). Similarly, under RCP 8.5 scenario it is projected to increase by $3.6 \%$ to $7.9 \%, 3.7 \%$ to $6.6 \%$ and $8.5 \%$ to $14 \%$ during the near, mid and late centuries respectively.

Season-wise analysis shows that the winter rainfall is projected to decrease in all three-time slices in RCP 4.5 and only in one (near century) under RCP 8.5. Tables 3 and 4 give the percentage of projected change in rainfall under RCP 4.5 and RCP 8.5 respectively. During mid century it is expected to increase in Balasore and Badhrak, and decrease in the other districts. Whereas in the end century it is projected to increase in all the districts, except Cuttack and Jagatsingpur. However, the percentage of projected decrease in winter rainfall is higher under RCP 4.5 compared to RCP 8.5. During the rainy season, rainfall is projected to increase under both the RCP scenarios, with the highest increase shown in RCP 8.5 scenario. The increase in rainfall is projected to be more at the end century under both the RCP scenarios. During summer rainfall is projected to decrease in the near century and increase in mid and late centuries under RCP 8.5. While under RC P4.5, the summer season rain- fall is projected to increase in all the districts, except Puri in the near century, and Cuttack and Puri in the mid century. During the late century it shows a decreasing trend in all the districts, except Bhadrak and Ganjam.

Based on RCP 4.5, the annual mean maximum temperature is expected to increase by $0.61-0.66^{\circ} \mathrm{C}, 0.68$ $0.72^{\circ} \mathrm{C}$ and $1.35-1.55^{\circ} \mathrm{C}$ during near, mid and late centuries respectively (Table 3 ), while under RCP 8.5 it is expected to increase by $1.79-1.97^{\circ} \mathrm{C}, 1.73-2.01^{\circ} \mathrm{C}$ and $3.08-3.44^{\circ} \mathrm{C}$ during near, mid and late centuries respectively (Table 4). As expected, the warming is maximum under RCP 8.5 compared to RCP 4.5. The season-wise projection shows that during winter the maximum temperature is expected to increase by $0.62-0.66^{\circ} \mathrm{C}, 0.65-$ $0.79^{\circ} \mathrm{C}$ and $1.48-1.72^{\circ} \mathrm{C}$ during the near, mid and late centuries respectively, under RCP 4.5 and by $1.95-$ $2.12^{\circ} \mathrm{C}, 1.97-2.26^{\circ} \mathrm{C}$ and $3.26-3.64^{\circ} \mathrm{C}$ during the near, mid and late centuries respectively, under RCP 8.5. In summer the mean maximum temperature is projected to increase by $0.61-0.72^{\circ} \mathrm{C}, 0.75-0.86^{\circ} \mathrm{C}$ and $1.28-1.62^{\circ} \mathrm{C}$ during the near, mid and late centuries respectively, under RCP 4.5. While under RCP 8.5 it is projected to increase by $1.76-2.11^{\circ} \mathrm{C}, 1.60-2.06^{\circ} \mathrm{C}$ and $2.99-3.43^{\circ} \mathrm{C}$ during the near, mid and late centuries respectively. During the rainy season, mean maximum temperature is projected to increase by $0.57-0.61^{\circ} \mathrm{C}, 0.65-0.68^{\circ} \mathrm{C}$ and $1.23-1.36^{\circ} \mathrm{C}$ during near, mid and late centuries respectively, under RCP 4.5 and $1.67-1.77^{\circ} \mathrm{C}, 1.61-1.76^{\circ} \mathrm{C}$ and $3.08-3.17^{\circ} \mathrm{C}$ during the near, mid and late centuries respectively, under RCP 8.5. Under RCP 8.5, the mean maximum temperature is projected to increase maximum during winter followed by summer and rainy season. While under RCP 4.5 , it is projected to increase maximum during summer 


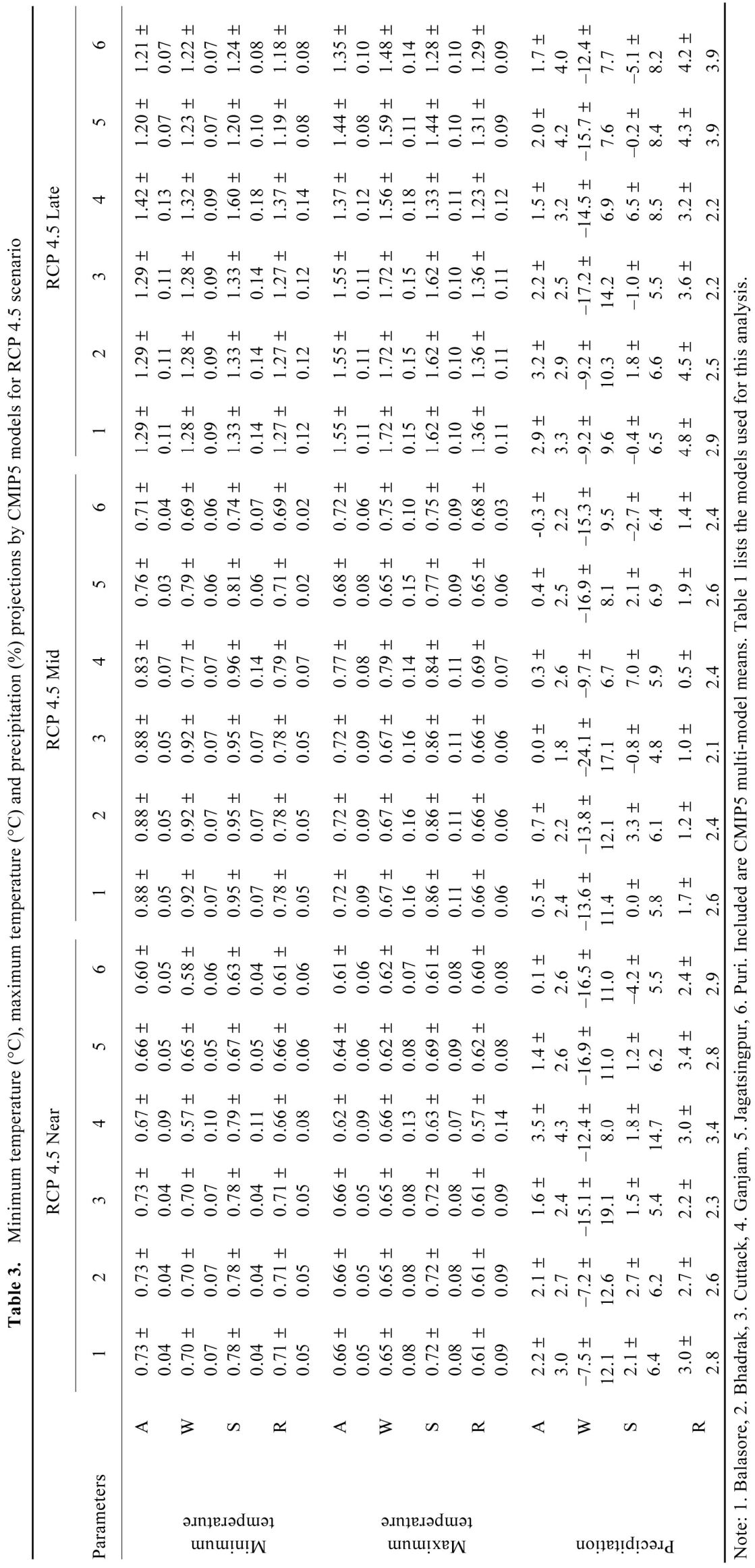




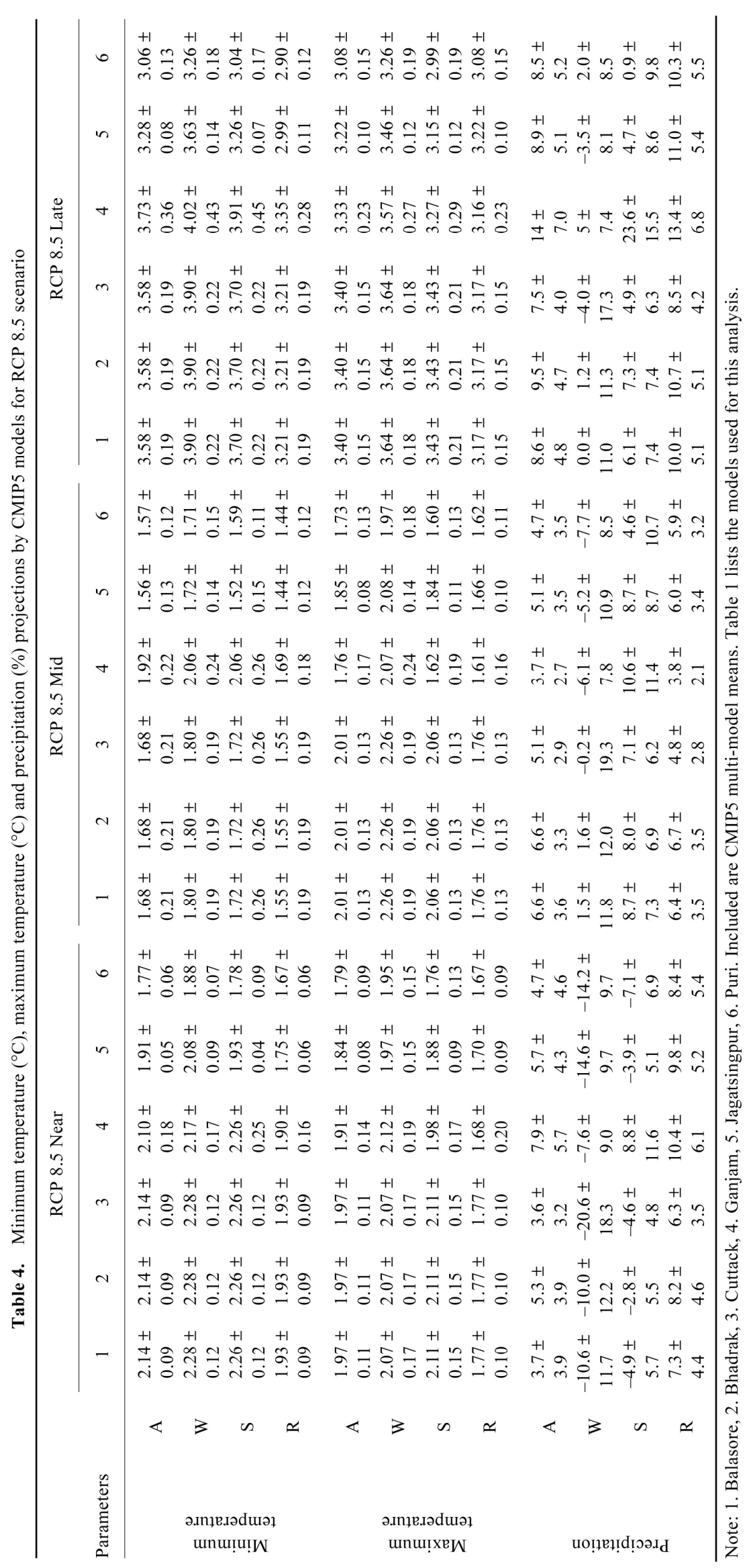


followed by winter and rainy season during near and mid centuries, and winter followed by summer and rainy season during late century. This clearly shows that the change of maximum temperature will be more during winter and summer compared to the rainy season under both the RCP scenarios.

The annual mean minimum temperature is expected to increases by $0.60-0.73^{\circ} \mathrm{C}, 0.71-0.88^{\circ} \mathrm{C}, 1.20-1.42^{\circ} \mathrm{C}$ (RCP 4.5) and $1.77-2.14^{\circ} \mathrm{C}, 1.56-1.68^{\circ} \mathrm{C}, 3.06-3.73^{\circ} \mathrm{C}$ (RCP 8.5) during the near, mid and late centuries respectively (Tables 3 and 4). The season-wise projection shows that during winter the mean minimum temperature is expected to increase by $0.57-0.70^{\circ} \mathrm{C}, 0.69-0.92^{\circ} \mathrm{C}, 1.22$ $1.32^{\circ} \mathrm{C}(\mathrm{RCP} 4.5)$ and $1.88-2.28^{\circ} \mathrm{C}, 1.71-2.06^{\circ} \mathrm{C}, 3.26$ $4.02^{\circ} \mathrm{C}$ (RCP 8.5 ) during the near, mid and late centuries respectively. In summer, it is projected to increase by $0.63-0.79^{\circ} \mathrm{C}, 0.74-0.96^{\circ} \mathrm{C}, 1.20-1.33^{\circ} \mathrm{C}(\mathrm{RCP} 4.5)$ and $1.78-2.26^{\circ} \mathrm{C}, \quad 1.52-1.72^{\circ} \mathrm{C}, \quad 3.04-3.91^{\circ} \mathrm{C} \quad(\mathrm{RCP} 8.5)$ during the near, mid and late centuries respectively. While in the rainy season the mean minimum temperature is projected to increase by $0.61-0.71^{\circ} \mathrm{C}, 0.69-0.78^{\circ} \mathrm{C}$, $1.18-1.37^{\circ} \mathrm{C}$ (RCP 4.5) and $1.67-1.93^{\circ} \mathrm{C}, 1.44-1.55^{\circ} \mathrm{C}$, $2.90-3.35^{\circ} \mathrm{C}$ (RCP 8.5) during the near, mid and late centuries respectively. Similar to mean maximum temperature, the mean minimum temperature during winter will have a large increase followed by summer and rainy season under the RCP 8.5 scenario. While under $\mathrm{RCP} 4.5$ it shows summer $>$ rainy season $>$ winter in the near century, summer $>$ winter $>$ rainy season in the mid century and rainy season $>$ summer $>$ winter in the late century.

\section{Discussion}

High temperature affects all the growth stages of rice, i.e. from germination to maturity and the severity depends on cropping season, growing region, cultivar and growth stage $^{22}$. In India, the rabi (post-rainy season) rice crop growth is slow during the vegetative stage due to cool weather $^{23}$. Conversely, the usual high and low temperatures during vegetative and flowering stage respectively, in kharif (wet season) are favourable for rice growth and development.

The heat wave and high temperature during flowering interfere in the reproductive process and reduce seed set by causing spikelet sterility ${ }^{24-26}$, and reduce grain yield by shortening the grain-filling duration and its rate ${ }^{27-31}$ and stimulating crop respiration. Temperatures above 35 at anthesis and lasting for more than $1 \mathrm{~h}$ can cause a reduction in the proportion of fertile spikelets and grain yield $^{32}$.

The results of this study show the increase in temperature (minimum and maximum) over the coastal plains of Odisha in all three-time slices under both the RCP scenarios. During kharif (rainy season) the minimum and maximum temperatures are expected to increase by $0.61-$ $1.37^{\circ} \mathrm{C}$ and $0.57-1.36^{\circ} \mathrm{C}$ respectively, under RCP 4.5 and $1.44-3.35^{\circ} \mathrm{C}$ and $1.61-3.17^{\circ} \mathrm{C}$ respectively, under $\mathrm{RCP}$ 8.5. However, rainfall during kharif is expected to increase under both the RCP scenarios and all three-time slices. The current temperature in coastal plains of Odisha is close to optimum for rice production during the kharif season. However, the increasing temperature may not be ideal for this. The kharif rice is sown in May and June, and it comes to flowering in September and October. The expected temperature rise during flowering may shorten the kharif rice duration and reduce grain yield, and the impact is expected to be more under RCP 8.5 over RCP 4.5. Growing suitable heat-tolerant culti$\operatorname{vars}^{33,34}$, change of sowing date, alternate cropping system, application of chemicals and providing supplemental irrigation $^{35}$ are the most effective measures to cope with the expected climate extreme ${ }^{36}$.

Besides rice, pulses (green gram, black gram, horse gram) and oilseeds (groundnut, sesame, toria) are generally cultivated in the rabi season. Rabi crops largely depend on winter and summer rainfall. Even two to three spells of rainfall during rabi season hugely benefit these crop. The future climate projection over coastal Odisha shows an increase in minimum and maximum temperatures by $0.57-1.32$ and $0.62-1.72$ respectively (under RCP 4.5), and 1.71-4.02 and 1.95-3.64 respectively (under RCP 8.5), during rabi season, with a decrease in rainfall up to $24.1 \%$ (RCP 4.5 ) and $20.6 \%$ (RCP 8.5 ). The expected climate change during rabi season over the coastal plains of Odisha presents both advantages and disadvantages. The increasing temperature provides an opportunity for early sowing of rabi rice crop. During December, the temperature over these coastal plains approaches near the base temperature (lowest temperature below which rice growth stops). Farmers delay the sowing of rabi rice due to low temperature in December ${ }^{23}$. The second crop of rice sown immediately after the harvest of kharif rice suffers from poor crop establishment and slow growth, especially early vegetative stage due to cool weather condition. The delayed sowing of rabi rice leads to terminal heat stress during flowering and maturity stage, and ultimately yield loss ${ }^{37,38}$. Conversely, the probability for the combined occurrence of dryspell and terminal heat stress is expected to increase in the coastal plains of Odisha due to the expected increase in temperature and decrease in rainfall during rabi season. The increase in temperature offers an opportunity for early sowing of rabi (dry season) crop. The early sowing of rabi crop reduces the chance of terminal heat stress and forced maturity ${ }^{39,40}$. Thus, expected temperature increase will benefit rabi rice by facilitating early sowing and avoiding terminal heat stress. It also facilitates efficient use of residual soil moisture (available soil moisture after the harvest of rice crop) by succeeding crops $^{41}$. 


\section{Conclusion}

Trend analysis of daily maximum and minimum temperature events in the coastal plains of Odisha over 31 years (1980-2010) revealed significant warming over the years. Future climate projection using CMIP5 multi-model mean also shows increasing trend over these coastal plains under both RCP scenarios. The rate of increase in temperature is more under RCP 8.5 compared to RCP 4.5. The duration of summer in coastal Odisha will be longer and winter will be shorter. Among the districts, Balasore, Bhadrak and Cuttack will experience more warming compared to the other coastal districts. The season-wise projection shows that the uncertainties in rainfall are larger in winter followed by summer and lowest in the rainy season under both RCP scenarios. The large uncertainty in winter and summer rainfall will harm the productivity of rabi crops like pulses and oilseeds. In kharif season, the yield and quality of rice crop are expected to be adversely affected by changing climate. The major limitation of this study is the use of coarse resolution GCM. The CMIP6 models have been improved in many aspects, such as higher resolution in the atmosphere and ocean, an improved representation of physics, and improved representation of aerosols in comparison to CMIP5. So future climate projections will be done using CMIP6 and compared with CMIP5 model output. However, the findings of this study can assist scientists and policymakers to develop appropriate coping strategies to anticipating climate change.

Conflict of interest: The authors report no potential conflict of interest.

1. GOI, Agricultural statistics at a glance, Government of India Ministry of Agriculture and Farmers Welfare Department of Agriculture, Cooperation and Farmers Welfare, Directorate of Economics and Statistics. Government of India, New Delhi, 2009.

2. GOI, Report on status of ground water quality in coastal aquifers of India, Government of India, Ministry of water resources, Central Ground Water Board, Faridabad, 2014, pp. 1-130.

3. Patnaik, U., Das, P. K. and Bahinipati, C. S., Analyzing vulnerability to climatic variability and extremes in the coastal districts of Odisha, India. Rev. Dev. Change, 2013, 18, 173-189.

4. IPCC, Change, IPOC, Climate change 2007: The physical science basis: Summary for policymakers. Geneva, IPCC, 2007.

5. Dupuis, I. and Dumas, C., Influence of temperature stress on in vitro fertilization and heat shock protein synthesis in maize (Zea mays L.) reproductive tissues. Plant Physiol., 1990, 94(2), 665-670.

6. Kim, H. Y., Horie, T., Nakagawa, H. and Wada, K., Effects of elevated $\mathrm{CO}_{2}$ concentration and high temperature on growth and yield of rice: II. The effect on yield and its components of Akihikari rice. Jpn. J. Crop Sci., 1996, 65(4), 644-651.

7. Barlow, K. M., Christy, B. P., O'leary, G. J., Riffkin, P. A. and Nuttall, J. G., Simulating the impact of extreme heat and frost events on wheat crop production: a review. Field Crops Res., 2015, 171, 109-119.

8. Venkateswarlu, B. and Prasad, J. V. N. S., Carrying capacity of Indian Agriculture: issues related to rainfed farming. Curr. Sci., 2012, 102(6), 882-888.
9. Mishra, P. K., Socio-economic impacts of climate change in Odisha: issues, challenges and policy options. Am. J. Clim. Change, 2017, 3(1), 93-107.

10. Jena, P. P., Climate change and its worst effect on coastal Odisha - an overview of its impact in Jagatsinghpur district. IOSR J. Humanities Soc. Sci., 2018, 23, 1-15.

11. Singh, B. R. and Singh, O., Study of impacts of global warming on climate change: rise in sea level and disaster frequency. Global warming - impacts and future perspective, 2012.

12. Taylor, K. E., Stouffer, R. J. and Meehl, G. A., An overview of CMIP5 and the experiment design. Bull. Am. Meteorol. Soc., 2012, 93, 485-498.

13. Meehl, G. A. et al., Decadal prediction: can it be skillful? Bull. Am. Meteorol. Soc., 2009, 90, 1467-1486.

14. Taylor, K., Stouffer, R. and Meehl, G., A summary of the CMIP5 experiment design, Program for Climate Model Diagnosis and Intercomparison (PCMDI), 2011.

15. Ramaraj, A., Geethalakshmi, V. and Bhuvaneswari, K., Understanding the uncertainty cascaded in climate change projections for agricultural decision making. Mausam, 2017, 68, 223-234.

16. Jena, P., Azad, S. and Rajeevan, M. N., CMIP5 projected changes in the annual cycle of Indian monsoon rainfall. Climate, 2016, 4, 14.

17. Moss, R. H. et al., The next generation of scenarios for climate change research and assessment. Nature, 2010, 463, 747-756.

18. Mishra, S. K., Sahany, S., Salunke, P., Kang, I. S. and Jain, S., Fidelity of CMIP5 multi-model mean in assessing Indian monsoon simulations. Npj Climate Atmos. Sci., 2018, 1(1), 1-8.

19. Rosenzweig, C. et al., The agricultural model intercomparison and improvement project (AgMIP): protocols and pilot studies. Agric. Forest Meteorol., 2013, 170, 166-182.

20. Ramaraj, A. P. and Geethalakshmi, V., Analysing the uncertainty in climate projected by RCP 4.5 over Coimbatore. Ecol., Environ. Conserv., 2014, 20(3), 125-128.

21. Chiew, F. H. S. and Siriwardena, L., Estimation of SIMHYD Parameter Values for Application in Ungauged Catchments 1, 2005.

22. Wahid, A., Gelani, S., Ashraf, M. and Foolad, M. R., Heat tolerance in plants: an overview. Environ. Exp. Bot., 2007, 61, 199223.

23. Pathak, A., Pathak, P. and Sharma, K., Recent development in Boro rice improvement and production for raising rice yield in Assam. Boro Rice IRRI-India Office, New Delhi, 2003.

24. Jagadish, S., Muthurajan, R., Oane, R., Wheeler, T. R., Heuer, S., Bennett, J. and Craufurd, P. Q., Physiological and proteomic approaches to address heat tolerance during anthesis in rice (Oryza sativa 1). J. Exp. Bot., 2010, 61, 143-156.

25. Lele, U., Food Security for a Billion Poor, American Association for the Advancement of Science, 2010.

26. Bahuguna, R. N., Jha, J., Pal, M., Shah, D., Lawas, L. M., Khetarpal, S. and Jagadish, K. S., Physiological and biochemical characterization of nerica-1-44: A novel source of heat tolerance at the vegetative and reproductive stages in rice. Physiol. Plant., 2015, 154, 543-559.

27. Matsui, T., Namuco, O. S., Ziska, L. H. and Horie, T., Effects of high temperature and $\mathrm{CO}_{2}$ concentration on spikelet sterility in indica rice. Field Crops Res., 1997, 51, 213-219.

28. Xie, X., Li, B., Li, Y. and Shen, S., High temperature harm at flowering in Yangtze river basin in recent 55 years. Jiangsu J. Agric. Sci., 2009, 25, 28-32.

29. Lin, C.-J., Li, C.-Y., Lin, S.-K., Yang, F.-H., Huang, J.-J., Liu, Y.H. and Lur, H.-S., Influence of high temperature during grain filling on the accumulation of storage proteins and grain quality in rice (Oryza sativa 1). J. Agric. Food Chem., 2010, 58, 10545 10552.

30. Rani, B. A. and Maragatham, N., Effect of elevated temperature on rice phenology and yield. Indian J. Sci. Technol., 2013, 6, 5095-5097. 
31. Ahmed, N. et al., Effect of high temperature on grain filling period, yield, amylose content and activity of starch biosynthesis enzymes in endosperm of basmati rice. J. Sci. Food Agric., 2015, 95, 2237-2243.

32. Yoshida, S., Fundamentals of rice crop science. Int. Rice Res. Inst., 1981, pp. 1-279.

33. Prasad, P., Boote, K., Allen Jr, L., Sheehy, J. and Thomas, J., Species, ecotype and cultivar differences in spikelet fertility and harvest index of rice in response to high temperature stress. Field Crops Res., 2006, 95, 398-411.

34. Chaturvedi, A. K., Bahuguna, R. N., Shah, D., Pal, M. and Jagadish, S. K., High temperature stress during flowering and grain filling offsets beneficial impact of elevated $\mathrm{CO}_{2}$ on assimilate partitioning and sink-strength in rice. Sci. Rep., 2017, 7, 1-13.

35. Zhang, B., Zheng, J., Huang, S., Tian, Y., Peng, L., Bian, X. and Zhang, W., Temperature differences of air-rice plant under different irrigated water depths at spiking stage. J. Appl. Ecol., 2008, 19, 87-92.

36. Khan, S. et al., Mechanisms and adaptation strategies to improve heat tolerance in rice. A review. Plants, 2019, 8, 508.

37. Kumar, P., Geneletti, D. and Nagendra, H., Spatial assessment of climate change vulnerability at city scale: a study in Bangalore, India. Land Use Policy, 2016, 58, 514-532.

38. Mishra, A. K. and Singh, V. P., Drought modelling - a review. J. Hydrol., 2011, 403(1-2), 157-175.
39. Khichar, M. L. and Niwas, R., Thermal effect on growth and yield of wheat under different sowing environments and planting systems. Indian J. Agric. Res., 2007, 41, 92-96.

40. Al-Karaki, G. N., Phenological development-yield relationships in durum wheat cultivars under late-season high-temperature stress in a semiarid environment. Int. Scholarly Res. Network, 2012, 2012, 1-7; doi:10.5402/2012/456856.

41. Das, R., Ali, M. E., Abd Hamid, S. B., Ramakrishna, S. and Chowdhury, Z. Z., Carbon nanotube membranes for water purification: a bright future in water desalination. Desalination, 2014, 336, 97-109.

ACKNOWLEDGEMENTS. This study was financially supported by the Department of Science and Technology, New Delhi (order no. DST/ CCP/MRDP/143/2017(G)). We thank India Meteorological Department, Pune, for providing historical weather data and the Director, ICAR-National Rice Research Institute, Cuttack for support during this study.

Received 14 October 2020; revised accepted 1 May 2021

doi: $10.18520 / \mathrm{cs} / \mathrm{v} 121 / \mathrm{i} 2 / 222-232$ 